\title{
Desenvolvimento rural no Brasil: os limites do passado e os caminhos do futuro
}

\author{
ZANDER NAVARRO
}

$\mathrm{N}$ OS ÚlTimos 50 anos, dois foram os momentos durante os quais a noção de "desenvolvimento" se alçou a um campo de singularidade histórica, introduzindo-se como uma daquelas idéias-força que atraem generalizado interesse, intensamente discutidas, orientando programas governamentais, instigando sofisticados debates intelectuais e, em especial, motivando grupos sociais interessados nos benefícios das mudanças associadas e esta noção. Nesses momentos, inscrito nas agendas sociais, o tema do "desenvolvimento" adentrou o campo da política e, assim, passou a permear e a determinar as expectativas e o jogo das disputas sociais.

O primeiro de tais períodos nasceria nos anos seguintes à Segunda Guerra, especialmente a partir da década de 50, estendendo-se até o final dos anos 70. Nesse longo período, instigado pela polarização da Guerra Fria e seus opostos modelos de sociedade e, particularmente, sob o impacto do notável crescimento econômico da época, que materializou um padrão civilizatório dominante, revolucionando o modo de vida e os comportamentos sociais, a possibilidade do desenvolvimento alimentou esperanças e estimulou iniciativas diversas em todas as sociedades. Seria assim apenas inevitável que o desenvolvimento rural, como subtema imediatamente derivado, fosse igualmente um dos grandes motores das políticas governamentais e dos interesses sociais, igualmente inspirando um crescente conjunto de debates teóricos. Na época, muitas das sociedades atualmente avançadas ainda mantinham parcelas significativas de sua população envolvidas em atividades agrícolas e/ou habitando áreas rurais (embora gradativamente menores); nos demais países, tais parcelas alcançavam muitas vezes proporções elevadas. Da mesma forma, era ainda significativo o peso econômico da agricultura nas contas nacionais, mesmo em países que então formavam o bloco mais avançado.

É também relevante indicar que neste mesmo período, após lenta acumulação de inovações anteriores, constituiu-se uma nova e acabada "compreensão de agricultura" que gradualmente se tornou hegemônica em todo o mundo, não apenas no plano científico, mas nos diferentes sistemas agrícolas dos países que a 
ela aderiram. Alicerçada no que foi genericamente intitulado de "revolução verde", materializou-se de fato sob um padrão tecnológico o qual, onde foi implantado de forma significativa, rompeu radicalmente com o passado por integrar fortemente as famílias rurais a novas formas de racionalidade produtiva, mercantilizando gradualmente a vida social e, em lento processo histórico, quebrando a relativa autonomia setorial que em outros tempos a agricultura teria experimentado. Com a disseminação de tal padrão na agricultura, desde então chamado de "moderno", o mundo rural (e as atividades agrícolas, em particular) passou a subordinar-se, como mera peça dependente, a novos interesses, classes e formas de vida e de consumo, majoritariamente urbanas, que a expansão econômica do período ensejou, em graus variados, nos diferentes países. Esse período, que coincide com a impressionante expansão capitalista dos "anos dourados" (1950-1975), é assim um divisor de águas também para as atividades agrícolas, e o mundo rural (re)nasceria fortemente transformado, tão logo os efeitos desta época de transformações tornaram-se completos.

A noção de desenvolvimento rural, naqueles anos, certamente foi moldada pelo "espírito da época", com o ímpeto modernizante (e seus significados e trajetórias) orientando também as ações realizadas em nome do desenvolvimento rural. No Brasil, por exemplo, já nos anos 70, sob a condução dos governos militares, um conjunto de programas foi implementado nas regiões mais pobres, o Nordeste em particular, sob a égide do desenvolvimento rural (pois em outras regiões o modelo era o da "modernização agrícola"). Em tal contexto, a transformação social e econômica - e a melhoria do bem-estar das populações rurais mais pobres - foi entendida como o resultado "natural" do processo de mudança produtiva na agricultura. Este último foi meramente identificado como a absorção das novas tecnologias do padrão tecnológico então difundido, acarretando aumentos da produção e da produtividade e, assim, uma suposta e virtuosa associação com aumentos de renda familiar, portanto, "desenvolvimento rural".

Já no conjunto dos países então alinhados com a órbita socialista as propostas não eram em sua essência diferentes no tocante aos formatos tecnológicos, modificando-se tão somente os aparatos institucionais, as formas de propriedade e a redistribuição dos eventuais resultados produtivos. As poucas exceções a este ideário produtivista que dominou aquele período (tanto à direita como à esquerda, saliente-se) também redundaram em experiências malsucedidas. Simbolicamente, apenas como ilustração, o caso da Tanzânia, que parecia ser um dos mais inspiradores naquela época, com sua política de desenvolvimento rural centrada nas comunidades de aldeias e nas lealdades étnicas (que ficou registrado na literatura sob a expressão de ujamaa), igualmente fracassou em seus objetivos econômicos e produtivos, embora deixando positivo rastro de práticas governamentais e uma nova institucionalidade que marcaria a trajetória posterior daquele país. Este primeiro período, portanto, esgotou-se no final dos anos 70 em decorrência 
dos insatisfatórios resultados das propostas de desenvolvimento rural implementadas em diferentes países, particularmente com relação à redução da pobreza rural, que pouco se modificou. Ainda que em alguns países - como a Índia e a China - os resultados produtivos fossem expressivos, aos poucos consolidou-se a percepção de que as compreensões sobre o desenvolvimento (e o desenvolvimento rural, em particular) haviam sido demasiadamente otimistas. Tal desencanto também associou-se, certamente, ao estancamento da fase econômica expansionista do pós-guerra (refreado já em meados dos anos 70) e, posteriormente, à vaga conservadora que gradualmente se instalou na virada daquela década. A partir dos anos 80, políticas inspiradas em enfoque que posteriormente seria rotulado de neoliberalismo, enfraquecendo fortemente o papel do Estado na condução eficaz de suas políticas, igualmente retirariam o desenvolvimento rural da cena de discussões.

Assim, o segundo momento sob o qual o tema ressurge é muito recente: vencida esta transição, que deixou os debates sobre o desenvolvimento na penumbra, este novo momento provavelmente foi demarcado a partir de meados da década de 90 . Nos anos recentes, as motivações para o reaparecimento do debate sobre o desenvolvimento (e o desenvolvimento rural) modificaram-se radicalmente, caracterizando-se muito mais, ao contrário do primeiro período, por uma percepção acerca da aparente impossibilidade do desenvolvimento ou, pelo menos, suas imensas dificuldades de materialização. Aliás, pode-se ousadamente afirmar que talvez a inquietude social e política gerada pela disseminação da desesperança com relação ao futuro é que, de fato, tenha reavivado o crescente interesse pelo tema do desenvolvimento.

Um complexo conjunto de novos processos sociais e econômicos - associados usualmente à expressão "globalização" - veio à lume, alterando radicalmente a estruturação societária da maior parte dos países e seus modelos convencionais de interpretação e, por conseguinte, as propostas de ação, governamentais ou aquelas oriundas da sociedade civil. Criou-se, como se sabe, um período de incertezas e riscos, talvez sem precedentes. Neste quadro de mudanças rápidas, profundas e inéditas, o tema desenvolvimento - e desenvolvimento rural gradualmente reapareceu no teatro dos debates e das disputas sociais, agora em escala global. Observe-se, por exemplo, a título de brevíssima ilustração, o atual e vigoroso debate sobre mudanças climáticas nascido a partir do chamado Protocolo de Kyoto, decorrente da culminação dos impactos ambientais experimentados nas últimas décadas, os quais têm nas formas predatórias de uso da terra um de seus componentes relevantes (embora não o principal). Parece inegável que este debate deverá gerar novos contornos nos próximos anos, gerando outras formas de gestão dos recursos naturais, provavelmente impositivas. Bastaria associar este fato à extraordinária revolução tecnológica em curso na agricultura para concluir-se, necessariamente, que os anos vindouros estarão (re)criando 
compreensões radicalmente diferentes sobre os sistemas agrícolas e o modo de vida rural. Assim, especificamente com relação ao desenvolvimento rural, muitas são as motivações para este ressurgimento. No Brasil, tem sido possível identificar algumas das razões que explicariam o surgimento de crescentes esforços sóciopolíticos de revalorização da "sociedade rural" e suas atividades produtivas, de seu modo de vida e suas características sócio-culturais, de suas organizações e propostas societárias, como serão apontadas adiante.

\section{O que é desenvolvimento rural?}

Embora pareça desnecessário tal esclarecimento, a relativa ausência de debate - acadêmico e político - abrangente e continuado no Brasil sobre desenvolvimento rural, que apenas recentemente parece se impor, torna-se relevante, ainda que sucintamente (e superficialmente), apresentar algumas diferenças conceituais. Sua oportunidade é reforçada, por exemplo, por verificar-se a não existência, no Brasil, de uma consolidada tradição de análise das políticas públicas para o mundo rural, que investigasse amplamente as iniciativas dedicadas ao desenvolvimento rural em nossa história agrária recente, não apenas com relação aos seus impactos, mas igualmente quanto à sua racionalidade e estratégia operacional (no estilo dos policy studies). O resultado é que há um conjunto de expressões sendo atualmente utilizadas de forma intercambiável, malgrado seus distintos significados.

Neste sentido, a primeira expressão é desenvolvimento agrícola (ou agropecuário). Aqui estaria se referindo exclusivamente às condições da produção agrícola e/ou agropecuária, suas características, no sentido estritamente produtivo, identificando suas tendências em um período de tempo dado. Refere-se, portanto, à base propriamente material da produção agropecuária, suas facetas e evolução - por exemplo, área plantada, produtividade, formatos tecnológicos, economicidade, uso do trabalho como fator de produção, entre outros tantos aspectos produtivos.

Outra expressão correlata, que engloba a primeira citada, bem mais ambiciosa analiticamente (e assim sujeita a enormes controvérsias) é desenvolvimento agrário. Normalmente, tal expressão refere-se a interpretações acerca do "mundo rural" em suas relações com a sociedade maior, em todas as suas dimensões, e não apenas à estrutura agrícola, ao longo de um dado período de tempo. Quase sempre "meta-narrativas", estudam as mudanças sociais e econômicas no longo prazo, reivindicando uma aplicação de modelos teóricos entre países e regiões. Sob tal expressão, as condições próprias da produção (o desenvolvimento agrícola) constituem apenas uma faceta, mas a análise centra-se usualmente também nas instituições, nas políticas do período, nas disputas entre classes, nas condições de acesso e uso da terra, nas relações de trabalho e suas mudanças, nos conflitos sociais, nos mercados, para citar alguns aspectos. Portanto, a "vida social rural" e sua evolução adentram tais análises em todos os seus aspectos. Normalmente, 
como são amplos painéis históricos sobre o mundo rural em um dado período, são estudos macro-sociais e pouca relevância é atribuída aos processos microsociais ou da vida cotidiana. Historiadores, economistas e sociólogos são seus principais autores, muitas vezes inspirados em enfoques estruturalistas (de variados matizes), ênfase nos processos históricos e recebendo, quase sempre, influência marxista - ou uma combinação de algumas dessas vertentes principais, na esteira da tradição teórica da economia política.

A lista desses estudos poderia ser extensa, mas tem como uma de suas características serem interpretações que vicejaram em maior número durante o que foi aqui referido como o "primeiro momento" dos estudos sobre o desenvolvimento rural. Apresentam enorme variabilidade e podem se inspirar em algumas obras clássicas, como O desenvolvimento do capitalismo na Rússia (Lenin, 1899). Esta obra pode ser considerada como um dos primeiros exemplos de um típico estudo sobre o desenvolvimento agrário, aplicado ao caso russo da segunda metade do século XIX. No mesmo veio, outros autores, como Chonchol (1994), analisaram o desenvolvimento agrário na América Latina, desde o período précolonial, enquanto Veiga (1991), não obstante o título de seu livro, dedicou-se ao desenvolvimento agrário selecionando a experiência de alguns países europeus entre os séculos XIX e XX. No Brasil, nos anos 70, até o início da década seguinte, alguns estudos perseguiram esta vertente. Entre outros, e sem hierarquia valorativa alguma, meramente como exemplos, o artigo de Lopes (1982) sobre o desenvolvimento do capitalismo agrário em São Paulo ou o livro de Guimarães (1979). Outro estudo típico nesta direção, igualmente inspirado em Lenin, seria o livro de Graziano da Silva (1981), também dedicado ao estudo do desenvolvimento agrário em São Paulo. Um pioneiro esforço teria sido o artigo de Goodman (1986), ao pretender analisar o Brasil agrário do final da Segunda Guerra até os anos da modernização da década de 70, enquanto Kageyama et al. (1990) propuseram estender sua interpretação sobre o desenvolvimento agrário tomando como ponto de partida a crise do complexo rural (na segunda metade do século XIX) até o chamado processo de industrialização da agricultura brasileira, iniciado nos anos 50 .

Esses estudos (entre outros, insista-se) têm em comum o fato de buscar na evolução dos determinantes macroestruturais, especialmente na dinâmica do capitalismo agrário do passado, a interpretação do presente e, também, uma indicação das possibilidades do futuro, sob um enfoque histórico, englobando os determinantes sociais, políticos e econômico-estruturais de um determinado período. Normalmente, como talvez esperado, são estudos que se inspiraram, em graus diversos, principalmente nas tradições intelectuais do marxismo. Outras tradições teóricas que legaram "teorias da sociedade" (como uma vertente weberiana, por exemplo), não estimularam a elaboração de estudos influentes neste campo, e os demais paradigmas, como o estrutural-funcionalismo, ainda 
em voga naqueles anos, também não fundamentaram a produção das ciências sociais interessadas em entender o desenvolvimento agrário brasileiro.

A terceira expressão que concorre neste esforço de melhor precisão é, exatamente, desenvolvimento rural. Neste caso, diferencia-se das anteriores por uma característica específica: aqui, trata-se de uma ação previamente articulada que induz (ou pretende induzir) mudanças em um determinado ambiente rural. Em conseqüência, o Estado nacional - ou seus níveis subnacionais - sempre esteve presente à frente de qualquer proposta de desenvolvimento rural, como seu agente principal. Por ser a única esfera da sociedade com legitimidade política assegurada para propor (e impor) mecanismos amplos e deliberados no sentido da mudança social, o Estado funda-se para tanto em uma estratégia préestabelecida, metas definidas, metodologias de implementação, lógica operacional e as demais características específicas de projetos e ações governamentais que têm como norte o desenvolvimento rural.

A definição do que seja exatamente "desenvolvimento rural”, em tais ações, igualmente tem variado ao longo do tempo, embora normalmente nenhuma das propostas deixe de destacar a melhoria do bem-estar das populações rurais como o objetivo final desse desenvolvimento (adotando indicadores de ampla aceitação). As diferenças, portanto, surgem nas estratégias escolhidas, na hierarquização dos processos (prioridades) e nas ênfases metodológicas. Além disso, certamente tais diferenças são fundamentadas em leituras de realidade (interpretações) distintas apontando objetivos igualmente distintos, ou seja, a análise do que tenha sido exatamente o desenvolvimento agrário fundamentará leituras (e projetos) correspondentes de desenvolvimento rural. Apenas como rapidíssimo exemplo: desenvolvimento rural, nos anos 70, necessariamente incluiria a intensificação tecnológica e a crescente absorção de insumos modernos pelos produtores, como parte de uma estratégia de aumento da produtividade e, como objetivo finalístico, a elevação da renda dos produtores. Em nossos dias, face à queda real dos preços recebidos pelos produtores e à virtual ausência de sistemas de ação governamental ao longo de tantos anos (especialmente a redução do financiamento), aqueles seriam componentes que poderiam se repetir sob a mesma forma? O conceito de desenvolvimento rural, em conseqüência, altera-se também ao longo do tempo, influenciado por diversas conjunturas e, principalmente, pelos novos condicionantes que o desenvolvimento mais geral da economia e da vida social gradualmente impõem às famílias e às atividades rurais.

Desenvolvimento rural, portanto, pode ser analisado a posteriori, neste caso referindo-se às análises sobre programas já realizados pelo Estado (em seus diferentes níveis) visando a alterar facetas do mundo rural a partir de objetivos previamente definidos. Mas pode se referir também à elaboração de uma "ação prática" para o futuro, qual seja, implantar uma estratégia de desenvolvimento rural, para um período vindouro (assim, existiriam diversas metodologias de 
construção de tal estratégia, bem como um amplo debate sobre seus objetivos e prioridades principais).

Há ainda duas outras expressões que merecem melhor entendimento e a tentativa de identificar seus contornos conceituais: desenvolvimento rural sustentável, a quarta expressão deste conjunto, surgiu em meados dos anos 80 a partir da crescente difusão da expressão mais geral, "desenvolvimento sustentável" (apoiada em crescente e copiosa literatura). Embora muitos autores e instituições pretendam atribuir a esta um sentido politicamente mais conseqüente do que a anterior (desenvolvimento rural), incorporando noções, por exemplo, de eqüidade social ou, mais ambiciosamente, atribuindo alguma suposta relação entre formas de organização social das famílias rurais mais pobres, fruto de "conscientização", e desenvolvimento rural sustentável, o foco central, neste caso, é bastante claro e mais limitado.

A idéia de sustentabilidade nasceu da crescente percepção acerca dos impactos ambientais do padrão civilizatório acelerado após a Segunda Guerra, cujas evidências empíricas multiplicaram-se a partir da década de 70. Neste sentido, o componente "sustentável" da expressão refere-se exclusivamente ao plano ambiental, indicando a necessidade de as estratégias de desenvolvimento rural (como antes definido) incorporarem uma apropriada compreensão das chamadas “dimensões ambientais". São assim meramente retóricas - e um típico exercício de wishful thinking - outras agregações à expressão, inclusive porque, "simplesmente atribuindo um nome não indica que algo possa existir de forma viável" (Yearley, 1996: 131). A tendência, desta forma, é que a expressão desenvolvimento rural seja acrescida, cada vez mais, do componente ambiental derivado da palavra sustentável. Embora certamente seja possível adicionar outros significados à noção de sustentabilidade (por exemplo, sustentabilidade política, social ou institucional, entre outras possibilidades), tais agregações já fazem parte do repertório analítico das tradições teóricas sobre o desenvolvimento rural. Por tal razão, mantendo-se o rigor necessário, o "sustentável" aqui refere-se tão somente aos padrões ambientais requeridos em ações movidas sob a ótica do desenvolvimento rural.

Por fim, a última expressão, desenvolvimento local, é também às vezes confundida com as demais expressões e livremente intercambiada, como se se referisse aos mesmos processos e fenômenos. Tal expressão é recente e deriva de duas grandes mudanças do período atual. Primeiramente a multiplicação de ONGs que, por atuarem normalmente em ambientes geograficamente mais restritos (a região ou o município), lentamente instituíram seu raio de atuação em tais ambientes e, em decorrência, criaram uma estratégia de "ação local", que se tornou ainda mais acentuada por oposição, quando os impactos dos processos globalizantes se aceleraram. A outra mudança refere-se aos processos de descentralização em curso em muitos continentes - a América Latina em particular (e o 
Brasil, em especial). Esta transferência de responsabilidades de Estados antes tão centralizados valorizou crescentemente o "local", no caso brasileiro, o município. É a convergência desses fatores, portanto, que tem introduzido o desenvolvimento local como outra das noções que gradualmente passam a ser orientadoras de diversas iniciativas, governamentais ou não.

A recente condensação de demandas sociais centradas em torno da noção de "agricultura familiar" igualmente tem reforçado esta tendência de reivindicar novos padrões de desenvolvimento rural que incluam mecanismos de repercussão local. A utilização desta noção, no Brasil, esbarra também em outro entrave: uma premissa falsa sobre a qual se sustenta. Por tal premissa argumenta-se que os "atores locais" já estão devidamente preparados para o desempenho de ações locais (ou, quando muito, podem se organizar rapidamente, se estimulados nesta direção). Contudo, um sumário conhecimento empírico das organizações representativas dos agricultores familiares, dos assalariados rurais e dos "semterra" em nosso país, no tocante ao seu funcionamento e aos seus limites operacionais, indicaria exatamente o inverso. Não obstante o enorme esforço já realizado e os novos e promissores formatos organizacionais sendo implementados, tais entidades são ainda insuficientes em número e, especialmente, quase sempre pouco representativas e de baixa capacidade de mobilização social. A escassa tradição associativista existente no campo brasileiro, como atualmente demonstram as evidências, é um claro limitador de iniciativas que tenham sua centralidade nos âmbitos exclusivamente locais.

Evidentemente, as fronteiras entre as expressões mencionadas não são inteiramente segmentadas e seus significados se interpenetram. Assim, será sempre necessário analisar-se corretamente o desenvolvimento agrícola para interpretar o desenvolvimento agrário de determinado país ou região, o que permitirá construir uma estratégia de desenvolvimento rural (ou, mais apropriadamente, por incluir dimensões ambientais, o desenvolvimento rural sustentável). Adicionalmente, sob tal estratégia, é provável que um conjunto de iniciativas no plano propriamente local (desenvolvimento local) será igualmente imprescindível.

Por fim, ressalta-se que "desenvolvimento rural” é também campo de produção do conhecimento e sujeito a arquiteturas analíticas inspiradas por tradições teóricas diversas e, muitas vezes, divergentes entre si. Não sendo possível no âmbito deste artigo (por razões de espaço) analisar-se os fundamentos e pressupostos de tal noção em diferentes momentos, deve-se destacar, contudo, que os estudos neste campo variaram fortemente nos últimos 40 anos, sob diversos ângulos. Um deles, apenas a título de exemplo, é a quebra da fronteira setorial associada à noção de desenvolvimento rural, no primeiro momento (antes citado) muito mais restrito à esfera agrícola, então sinônimo do rural. Dos anos 90 em diante, a própria significação do que é o "rural" tem sido objeto de aceso debate entre os estudiosos do tema, e seus significados vêm sendo redimensionados, deixando 
para trás sua identificação com o meramente agrícola. Bastaria, por exemplo, lembrar o debate recente - ainda essencialmente europeu - sobre a "multifuncionalidade" da agricultura que, do ponto de vista empírico, amplia notavelmente para muito além do estritamente rural, o rol de significados para a agricultura. $\mathrm{Ou}$, ainda, de imprevisíveis resultados para a estruturação do mundo rural e analiticamente muito mais complexa, a recentíssima discussão que agrega sistemas alimentares, desenvolvimento agrário e a "efervescente biopolítica das agrobiotecnologias" (Goodman, 2001: 183), que lentamente revoluciona inclusive a própria ontologia herdada da modernidade, cuja radical antinomia entre sociedade e natureza também vai sendo gradualmente erodida.

\section{Desenvolvimento rural e seus limites no Brasil}

Aceitando-se, ainda que superficialmente, a conceituação já apontada, e imaginando-se a elaboração de uma estratégia que promovesse o desenvolvimento rural no Brasil, seria necessário considerar, primeiramente, que o crescimento econômico e as transformações sociais e políticas (sobretudo as lições e os resultados do desenvolvimento agrário brasileiro) nas últimas três ou quatro décadas criaram condições e circunstâncias inteiramente novas para a materialização de tal objetivo. Atualmente há um conjunto de limites que, se secundarizados, provavelmente condenariam ex-ante qualquer iniciativa no sentido do desenvolvimento rural. Tais limites, se somados àqueles estruturalmente existentes e de origem mais remota, tornam de fato muito mais complexa a implementação dessas mudanças, não apenas quanto à sua racionalidade intrínseca, mas também do ponto de vista operacional. Além disso, embora não discutidos neste texto, são cada vez mais determinantes os limites operados por uma nova ordem internacional que vêm sendo materializada nos anos recentes. A abertura comercial e o acirramento concorrencial derivado da globalização têm significado, de fato, um gradual "encurralamento" das opções que se apresentam ao mundo rural. Como resultado, o poder de manobra dos Estados nacionais para erigir programas de desenvolvimento rural que mantenham alguma autonomia própria tem sido igualmente reduzido com o passar dos anos.

O primeiro desses limites reside exatamente na extrema heterogeneidade das atividades agrícolas e rurais no Brasil, diferenciação que foi exacerbada intensamente no período recente, quando diversas regiões (ou atividades intra-regionais) sofreram forte intensificação econômica e dinamismo tecnológico. Em oposição, outras partes do país rural parecem ainda dormitar em contextos do passado, seja no plano da (falta de) integração econômica, seja no que concerne à natureza das relações sociais e políticas, que permanecem distantes de padrões de institucionalidade satisfatórios, fruto de processos políticos que Martins (1994) apropriadamente intitulou de "o poder do atraso". Embora algumas dessas diferenças tenham sido atenuadas, especialmente pela difusão dos meios de comunicação e por ampliação da capilaridade dos meios de transporte, tornando excepcionais as 
regiões agrárias relativamente isoladas, ainda são muito diferenciadas entre si as diversas partes do mundo rural brasileiro, sob vários aspectos. Para uma estratégia de desenvolvimento rural, portanto, esta diversidade apresenta-se como um primeiro limite de formidável complexidade por exigir iniciativas institucionais marcadamente distintas. À luz do quase caótico padrão de ocupação do território e das terras agrícolas, que tem sido a marca do último meio século - especialmente nas regiões do Centro-Oeste e do Norte -, esta heterogeneidade impõe decisões igualmente diferentes, se o desenvolvimento rural vier a ser um objetivo maior das decisões nacionais. Há que se aceitar, portanto, o pressuposto da relativa desimportância atual de uma "questão agrária nacional" (e, até mesmo, uma "questão agrícola") que a herança marxista do passado insiste em relevar, ignorando as mudanças recentes. Existem, entretanto, diversas "questões regionais" que, enfocadas corretamente a partir de suas especificidades, poderiam gerar um padrão interdependente, cumulativo e virtuoso animando o desenvolvimento rural no país.

Alguns exemplos são evidentes em si mesmos - quando confrontadas as realidades agrárias das diversas regiões - ressaltando a relação entre o limite da diferenciação inter-regional e as soluções possíveis. O Nordeste, por exemplo, que recebe um enorme contingente populacional imerso em situação de pobreza rural associada a dramáticos indicadores sociais, certamente exigirá intervenções iniciais de mais forte impacto, o primeiro deles no campo fundiário, alterando fortemente a distribuição da propriedade da terra. Um radical programa de reforma agrária deveria ser dirigido a esta região, realmente modificando os índices de Gini atualmente existentes na maior parte de suas micro-regiões, rebaixando-os para parâmetros que não ultrapassassem 0,5 . Articulado a programas centrados em educação, renda mínima e acesso a serviços de saúde, uma forte reestruturação fundiária parece ser o foco central que poderia retirar a região não apenas do estado de pobreza material e baixas condições de vida que historicamente a caracteriza, mas igualmente eliminar os mecanismos de dominação política que, de fato, são os maiores responsáveis por seu atraso.

Mas, seria a reforma agrária, ainda que pontualmente, o foco para as demais regiões? Provavelmente não. Uma estratégia de desenvolvimento rural nacional que considerasse a heterogeneidade referida não poderia repetir, por exemplo, a atual estratégia de multiplicação de assentamentos rurais na região Norte do país, implementada sem qualquer salvaguarda ambiental. Particularmente, sem prever o imenso estoque de riqueza potencial que esta região poderá gerar, em um ambiente (muito provavelmente, em curto prazo) no qual os propostos mecanismos de "desenvolvimento limpo", instituindo a troca de atividades de absorção de carbono por créditos internacionais, já estejam em pleno funcionamento. Desbravar áreas para a formação de assentamentos rurais, que normalmente respondem por sofrível manejo dos recursos naturais, parece ser, pelo contrário, uma política de antidesenvolvimento rural. 
Não se estendendo sobre as outras regiões, mencione-se por fim o caso singular dos três estados do Sul onde a produção agrícola alcança relevante significação econômica e onde, com relação ao restante do país, predomina expressivo contingente de agricultores familiares. Tais famílias, em função dos processos de modernização agrícola típicos do desenvolvimento agrário recente, integraram-se fortemente aos diferentes mercados e exercitaram a transformação tecnológica em suas propriedades. As gerações mais jovens de agricultores, inclusive, encontram-se atualmente imbuídas de uma racionalidade de gestão da propriedade que as aproxima muito mais do modelo do farmer norte-americano, que simboliza o pleno desenvolvimento do capitalismo agrário. Nesta região, uma política de reforma agrária (se o objetivo é o desenvolvimento rural, ressalte-se) perdeu inteiramente o seu significado histórico e, atualmente, seria muito mais demandada uma política de crédito fundiário associada ao financiamento de instalação de atividades produtivas para as famílias mais jovens recém-constituídas.

A esta política seriam associados sistemas de crédito para estimular a comercialização e a agroindustrialização de produtos agrícolas, formação de empreendimentos intermunicipais destinados ao escoamento de produtos tipicamente de exportação, acordos setoriais em algumas cadeias produtivas de alta densidade econômica (avicultura e suinocultura, por exemplo) que definissem os ganhos de todos os participantes, inclusive dos produtores integrados, entre outras políticas que poderiam ser mencionadas. A profissionalização dos produtores, nesta região, parece ser a meta imediata e mais estratégica; as respostas seriam certamente rápidas, à luz das características sócio-culturais e das mudanças econômicas e produtivas operadas no período recente.

Finalmente, não sendo possível neste espaço maior aprofundamento, é importante pelo menos ressaltar que as mudanças das últimas décadas também instituíram outros limites, que certamente fazem parte do rol de premissas fundantes de uma estratégia nacional de desenvolvimento rural. Alguns deles, apenas para exemplificar: o fato de ter sido completada a "colagem" entre produção de alimentos e matérias-primas agrícolas e a demanda agregada, não existindo concretamente problemas de oferta de tais mercadorias em nosso país. Isto significa que qualquer estratégia de aumento da área plantada, da ocupação de novas áreas e de expansão da produção somente poderia ser arquitetada se igualmente concretizado um aumento expressivo nas exportações ou um processo de distribuição da renda pessoal (ou ambos, o que seria o ideal). Mesmo aqui, contudo, as barreiras são imensas: nos anos 90 verificou-se a crescente formalização de acordos que, na prática, têm basicamente significado o fechamento dos mercados agrícolas para os países grandes exportadores do Terceiro Mundo, como o Brasil, impedindo notavelmente as tentativas de aumento das exportações agrícolas.

Encontrado tal limite estrutural de aumento da atividade produtiva no campo (tão bem demonstrado em Nunes, 1999, ou, sob outra perspectiva de análise, 
em Alves et al., 1999), decorrem ainda outras barreiras, como o virtual estancamento do mercado de trabalho rural ou a própria dinamização das atividades agroindustriais e das estruturas de comércio correspondentes, que tem crescido quase sempre apenas em resposta ao aumento vegetativo da demanda.

Tais limites (e vários outros que não foram aqui discutidos) constituem a estruturação prévia que condiciona qualquer processo de rejuvenescimento social e econômico no campo brasileiro. Sem considerá-los devidamente, não se construirá um processo de desenvolvimento rural no Brasil.

\section{As mudanças possíveis}

Portanto, por onde começar? O desafio inicial, por curioso que pareça (embora não surpreenda) é primeiramente político e ideológico. Consistiria em aceitar que, nesta quadra da história, o padrão econômico e o regime político que sustentam a sociedade brasileira estariam ancorados no capitalismo e a sua superação, sequer remotamente, encontra-se no horizonte. Parece ser esta uma excêntrica observação, mas no Brasil é necessária porque a orientação anti-sistêmica ainda fundamenta a maior parte dos estudos sobre o mundo rural, sob discursos quase naturalizados. As organizações populares do campo, por outro lado, igualmente motivadas pela mesma ótica, encontram-se imersas em profundas incertezas ideológicas, não constituindo forças anticapitalistas, nem mesmo se posicionando como eficazes reformadoras do status quo. Conseqüentemente, se for aceita a primeira observação, a pergunta crucial seria: quais seriam as possibilidades de enraizar um regime político radicalmente democrático, e de reduzir ou socialmente controlar a lógica excludente do sistema econômico, tornada ainda mais aguda pelas características do desenvolvimento recente, inclusive as monumentais restrições de tantas ordens - especialmente aquelas no campo macroeconômico relativas ao nível de investimentos, ao acirramento concorrencial nos mercados externos e interno, à concentrada distribuição de renda, mas também às restrições tecnológicas, ambientais, entre outras?

Novamente, aqui repousa outro impasse político, pois as soluções em face desses diferentes fatores requerem, para seu sucesso, a formação de uma coalizão entre forças sociais de distintas orientações políticas. Esta "aliança pelo desenvolvimento rural", se o objetivo for de fato garantir um processo de mudanças que seja nacional, efetivamente democratizante, e reduza gradativamente as desigualdades sociais e econômicas - respeitada a heterogeneidade já citada e, portanto, os ritmos e a natureza diferenciada do processo nas regiões -, não pode ser restritiva do ponto de vista de seus participantes.

A coalizão necessariamente incluiria, como deveria ser evidente, não apenas os "setores populares", mas também a maioria do empresariado agrícola, e certamente a totalidade de seu setor mais modernizado, aos quais a principal condicionalidade a ser negociada seria a sua submissão a dois imperativos inadiáveis: 
primeiramente, o primado da função social da propriedade, especialmente no tocante à rigorosa aplicação da legislação trabalhista no campo, acompanhada de um acordo de melhoria real gradativa dos salários rurais; de outro lado, a igualmente rigorosa conformação às exigências das leis de proteção ambiental atualmente em vigor. É politicamente quimérico ir além desta fronteira na quadra histórica em que vivemos, considerando a responsabilidade de tais setores no total da produção agrícola.

Do conjunto dos grandes proprietários territoriais, há apenas um subsetor que deveria sair como definitivo e anunciado perdedor: o composto por aqueles que usam a terra especialmente como reserva de valor e como arma de reprodução política, mesmo que prioritariamente confinados somente ao Nordeste brasileiro, como antes apontado. Neste sentido, seria necessário concordar que a atualidade da reforma agrária como "questão nacional", em face do desenvolvimento agrário dos últimos 50 anos, deixou de existir no Brasil, e sua necessidade, nos dias atuais, distancia-se de qualquer patamar politicamente decisivo. Reforma agrária, atualmente, apenas responde à oportunidade de aumentar o estoque de ocupações rurais, o que é crucial apenas em regiões determinadas, particularmente no Nordeste, mas apenas pontualmente nos demais casos.

As organizações, tanto patronais quanto aquelas do campo popular, estariam dispostas a subscrever uma agenda que contivesse tal preâmbulo? É improvável, mas sem esta concordância dificilmente um projeto de desenvolvimento rural será de fato desencadeado no Brasil, pois as assintonias políticas (e as realidades do mundo rural) estariam imersas em abismos ideológicos de impossível superação e, menos ainda, de uma convergência pelo menos parcial.

Por que um processo de desenvolvimento rural deveria se moldar sobre as limitações históricas com as quais nos defrontamos no presente? São muitas as razões. Primeiramente, porque não há mais um Estado capaz de comandar uma forte intervenção no campo, como fizeram os governos militares na década de 70 , promovendo uma verdadeira revolução produtiva e tecnológica que transformou radicalmente não apenas as estruturas de produção, mas igualmente instituiu novos padrões de racionalidade e os comportamentos sociais em tantas regiões rurais. Examine-se, como ilustração, o desmonte dos serviços de extensão rural e assistência técnica, cuja existência no Nordeste, Centro-Oeste e Norte atualmente é apenas virtual; ainda mais, o seu reerguimento seria extremamente problemático. Não agregando outros argumentos, bastaria igualmente ressaltar que nos anos recentes observou-se a implementação de políticas de privatização que, na prática, quase eliminaram, por exemplo, a presença estatal no chamado "Dl para a agricultura", isto é, o setor industrial à montante das atividades agrícolas (Graziano da Silva, 1996).

Esta redução da capacidade de intervenção do Estado, se somada aos impactos da privatização em outras áreas (por exemplo, infra-estrutura), vem restringindo fortemente as chances de propor uma efetiva política de desenvol- 
vimento rural. Se forem incluídas, igualmente, as demais amputações na capacidade de ação e intervenção do Estado (Leite, 2001) nos anos recentes, tornam-se ilusórias as propostas que parecem apenas pretender a reconstituição do passado, quando o suporte normativo e financeiro para este objetivo deixou de existir.

Em segundo lugar, porque mesmo que "o rural" seja muito mais expressivo do que de fato as estatísticas indicam (como demonstrado por Veiga et al., 2001), é improvável que a forte destinação de recursos públicos para o mundo rural se sustente em racionalidade decisória, apoio social amplo e legitimidade política, em um país que se urbanizou (inclusive culturalmente) de forma tão extraordinária, especialmente nas últimas quatro décadas. Em vista da evidência que diz ser satisfatória a oferta de alimentos e matérias-primas no Brasil (dada a distribuição de renda existente), haveria até mesmo a possibilidade do argumento da desnecessidade de investir maiores recursos no campo, pois as prioridades sociais seriam outras.

Além disto, deve-se considerar também que o foco prioritário de uma ação destinada ao desenvolvimento rural modificou-se no período recente. Embora ainda de restrita aceitação, inclusive entre estudiosos - o que é, em alguma medida, surpreendente -, nenhuma estratégia de desenvolvimento rural poderá se assentar sem uma prioridade ambiental, especialmente no tocante ao manejo de recursos naturais como seu pressuposto. A recente crise energética brasileira desnudou, talvez com clareza, que antes de ser decorrente de investimentos insuficientes e/ ou mudanças no regime de chuvas, a redução do potencial energético deriva de uma profunda alteração nos sistemas agrícolas e sua expansão nas últimas três ou quatro décadas. Sua conformação seguiu uma lógica ambiental predatória que reduziu dramaticamente a capacidade de absorção hídrica dos solos brasileiros, eliminando nascentes e afetando a malha de cursos de água e, por extensão, a vazão dos rios principais das diferentes bacias hidrográficas (o caso da bacia do rio São Francisco sendo paradigmático).

Rejuvenescer, portanto, a capacidade produtiva dos solos brasileiros sob nova orientação ambiental requer uma diretriz que seja primeiramente fundada em aprimorados sistemas de manejos de recursos naturais. Felizmente, no caso brasileiro existem as experiências acumuladas nos estados do Paraná e de Santa Catarina, onde dois exemplares projetos (o "Paraná Rural" e o "Microbracias", respectivamente) desencadearam uma nova racionalidade sócio-ambiental de uso da terra que pode produzir cenários potencialmente promissores de desenvolvimento rural (Navarro, 1999). Tais casos poderiam ensejar lições relevantes para a construção de um conjunto de ações transformadoras do mundo rural brasileiro.

Outro foco igualmente primordial com relação às perspectivas do passado refere-se aos fenômenos de democratização dos municípios, sob o impacto das mudanças políticas do período recente. Crescentes inovações na gestão pública, ampliando a participação e o controle social sobre os fundos públicos ao instalar 
maior transparência e mecanismos de responsabilização - ou, em termos genéricos, mais ampla e eficaz governance-, provavelmente significam uma profunda transformação sócio-política em andamento, cujos contornos mais concretos são ainda imprecisos.

Desenvolvimento rural, portanto, não se restringe ao "rural estritamente falando" - famílias rurais e produção agrícola - nem exclusivamente ao plano das interações sociais, também principalmente rurais - comunidades, bairros e distritos rurais, por exemplo -, mas necessariamente abarcam mudanças em diversas esferas da vida social as quais, se têm por limite mais imediato de realização o município, podem estender-se para horizontes territoriais mais extensos, como provavelmente ocorrerá em curto prazo. Parecem assim desaparecer definitivamente o corte ruralurbano e as formas de sociabilidade, igualmente demarcadas por tal segmentação.

Sob tal lógica argumentativa, pertence mais ao campo próprio da ideologia e menos da realidade dos sistemas agrícolas e agrários brasileiros a proposição que insiste na necessidade exclusiva de "organização social", apontada quase sempre como a única exigência (principalmente política) para promover as desejadas mudanças. Ainda menos, a perspectiva que julga existirem virtualidades em orientações unívocas (como a ênfase na multiplicação de "assentamentos rurais", por exemplo).

Conforme crescentemente aceito pela literatura, fruto do aprendizado acumulado em meio século de estudos neste campo, estratégias de desenvolvimento rural necessitam reconhecer, primeiramente, a multitude dos "estilos de agricultura" existentes e aqueles potenciais, qual seja, a infinita possibilidade de variações que os sistemas agrícolas e a vida rural podem assumir (van der Ploeg, 1990). Desta forma, ações voltadas ao desenvolvimento rural requerem, é fato, que as representações políticas construídas pelas famílias rurais sejam presentes e ativas (a organização), mas também considerem o significado da heterogeneidade nas práticas agrícolas (e a decorrente organização da agricultura). Igualmente, afiram corretamente os resultados dos processos de mercantilização e incorporação institucional verificados no Brasil no período mais recente, que determinaram processos de trabalho e estratégias das famílias rurais extremamente distintas, quando comparadas as regiões.

Finalizando, ainda dentro de um quadro mais geral de vetores fundantes na elaboração de uma estratégia de desenvolvimento rural no Brasil, salienta-se que nenhum dos diagnósticos e conjuntos de propostas e estudos já submetidos ao escrutínio público parece ser suficiente para oferecer instrumentos analíticos adequados à reconstrução do mundo rural e suas potencialidades sociais e produtivas, considerados os desafios e impasses existentes. Há contribuições de imensa relevância, tanto no Brasil, como é o caso do Projeto Rurbano (Graziano da Silva, 1999) ou da proposta contida em Veiga et al. (2001) quanto os novos arcabouços analíticos de crescente aceitação internacional, como a perspectiva de "formas de vivência" (ou livelihood strategies, veja-se Ellis, 2000). 


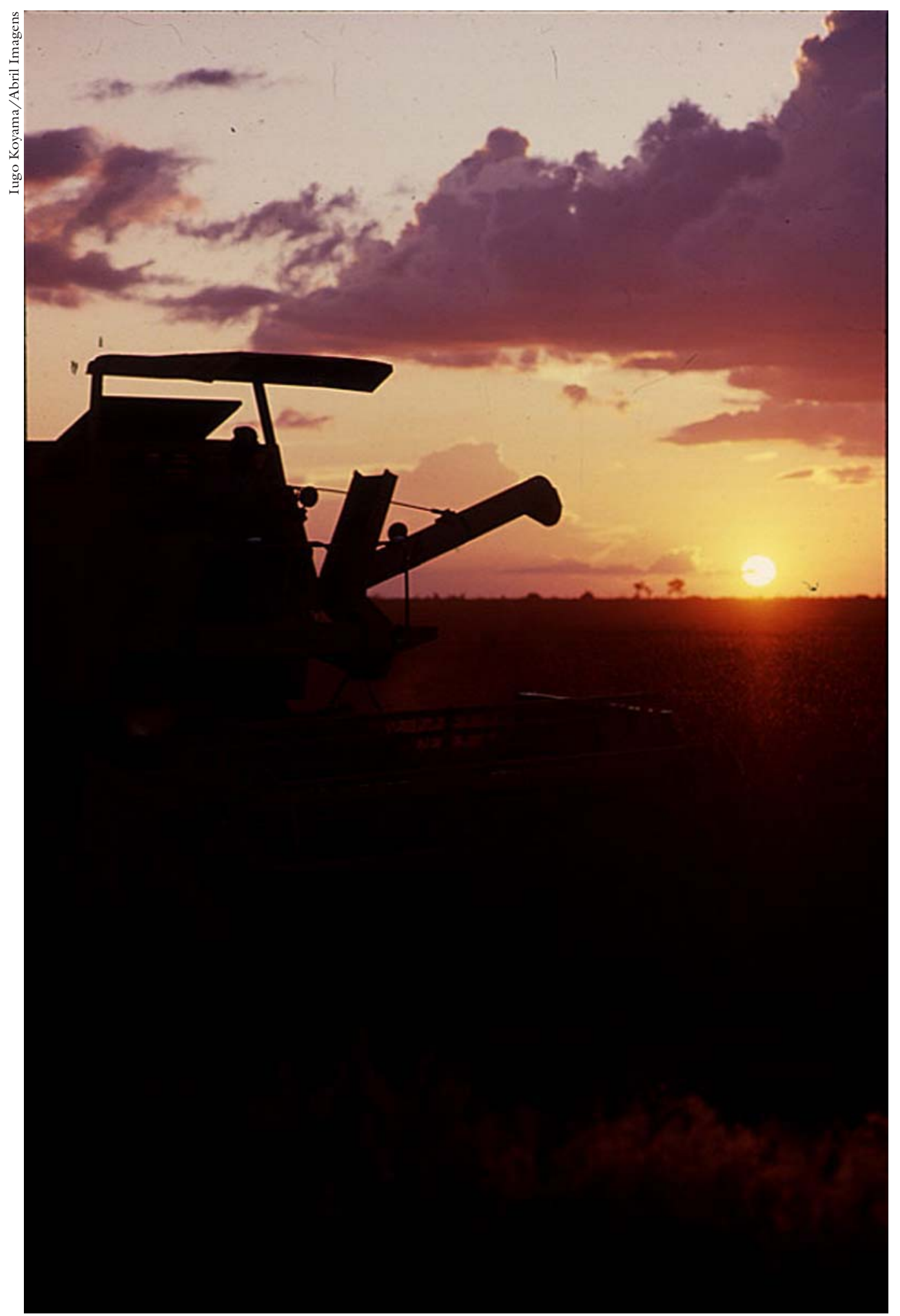

Nenhuma estratégia de desenvolvimento rural poderá se assentar sem uma prioridade ambiental ... 
Essas inovadoras contribuições, embora aportando consideráveis avanços, ainda não propuseram claras trilhas para o desenvolvimento rural, pois o processo de mudanças deverá ser múltiplo, interdependente, cumulativo e diversificado em planos territoriais e sociais variados. Desde o interior dos estabelecimentos rurais, onde a difusão da chamada "agricultura do conhecimento" não pode deixar de ser o modelo principal, aos planos societários para além das cercas das propriedades, inclusive nos próprios municípios nos quais o desenvolvimento rural se associe à intensificação da participação social e ao aperfeiçoamento da "governança" local, sedimentados por uma radicalização democrática que seja a principal arma política a revalorizar o mundo rural como uma das opções da sociedade. Assim, um esforço para ampliar o debate entre os diferentes proponentes, estudiosos e organizações rurais, sem pré-condições (especialmente as derivadas das âncoras ideológicas), parece ser o maior desafio atualmente existente entre aqueles que sonham ver concretizados os processos de desenvolvimento rural no Brasil que realmente instituam processos de emancipação social e, especialmente, renovem as esperanças para as famílias rurais.

Referências bibliográficas

ALVES, Eliseu et al. O empobrecimento da agricultura brasileira. Revista de Politica Agricola, v. VIII, n. 3, p. 5-19, 1999.

CHONCHOL, Jacques. Sistemas agrarios en América Latina. De la etapa prehispánica a la modernización conservadora. Santiago, Fondo de Cultura Económica, 1994.

ELLIS, Frank. Rural livelihoods and diversity in developing countries. Oxford, Oxford University Press, 2000.

GOODMAN, David. Economia e sociedade rurais a partir de 1945. In: BACHA, Edmar \& KLEIN, Herbert S., A transição incompleta. Brasil desde 1945. Rio de Janeiro, Paz e Terra, 1986, p. 113-173.

Ontology matters: the relational materiality of nature and agro-food studies. Sociologia Ruralis, v. 41, n. 2, p. 182-200, 2001.

GRAZIANO DA SILVA, José. Progresso técnico e relações de trabalho na agricultura. São Paulo, Hucitec, 1981.

A nova dinâmica da agricultura brasileira. Campinas, Instituto de Economia, Unicamp, 1996.

Onovo rural brasileiro. Campinas, Instituto de Economia, Unicamp

(Série Pesquisas, 1), 1999.

GUimarãeS, Alberto Passos. A crise agrária. Rio de Janeiro, Paz e Terra, 1979. 
KAGEYAMA, Angela et al. O novo padrão agrícola brasileiro: do complexo rural aos complexos agroindustriais. In: DELGADO, Guilherme Costa et al. (orgs.), Agricultura e políticas públicas. Brasília, IPEA, (Série IPEA, 127), 1990, p. 113-223.

LEITE, Sérgio (org.) Políticas públicas e agricultura no Brasil. Porto Alegre, Editora da Universidade, 2001.

LOPES, Juarez Rubens Brandão. Empresas e pequenos produtores no desenvolvimento do capitalismo agrário em São Paulo (1940-1970). Estudos Cebrap, n. 22, p. 41-110, 1982.

MARTINS, José de Souza. O poder do atraso. Ensaios de sociologia da história lenta. São Paulo, Hucitec, 1994.

NAVARRO, Zander. Manejo de recursos naturais e desenvolvimento rural: um estudo comparativo em quatro estados brasileiros (lições e desafios). Porto Alegre, 1999 [manuscrito não publicado].

NUNES, Rubens. Agricultura familiar: custos de transação, forma organizacional e eficiência. São Paulo, 2000. Tese (doutoramento), Faculdade de Economia, Administração e Contabilidade da Universidade de São Paulo.

VAN DER PLOEG, Jan Douwe. Labor, markets, and agricultural production. Boulder, Westview Press, 1990.

VEIGA, José Eli da. O desenvolvimento agrícola. Uma visão histórica. São Paulo, Hucitec, 1991.

VEIGA, José Eli da et al. O Brasil rural precisa de uma estratégia de desenvolvimento. Texto para discussão n. 1. Brasília, MDA/NEAD, 2001.

YEARLEY, S. Sociology, environmentalism, globalization. London, Thousand Oaks, 1996.

Zander Navarro é professor do Programa de Pós-graduação em Desenvolvimento Rural da Universidade Federal do Rio Grande do Sul (PGDR/UFRGS).

znavarro@portoweb.com.br

O autor agradece os atentos comentários de José Graziano da Silva à versão preliminar deste artigo. Ressalta, contudo, como é praxe, que é inteiramente responsável pela versão final. 